\title{
A Rotating Target Wheel System for Gammasphere
}

\author{
John P. Greene, Joseph W. Falout, Christopher J. Lister, and Bruce G. Nardi \\ Physics Division, Argonne National Laboratory, 9700 S. Cass Ave., Argonne, IL 60439
}

John D. Fox

Physics Department, Florida State University, Tallahassee, FL, 32306

Abstract

A description is given for a low-mass, rotating target wheel to be used within the Gammasphere target thatmbect This system was developed for experiments employing high beam currents in order to extend lifetimes of targets usif low melting point target material. The design is based on a previously successful implementation of rotating target wheels for the Argonne Positron Experiment (APEX) as well as the Fragment Mass Analyser (FMA) at ATLAS (Argonne Tandem Linac Accelerator System). A brief history of these rotating target wheel systems is given as well as a discussion on target preparation and performance.

\section{INTRODUCTION}

In order to obtain the highest possible beam currents per experimental demands, target rotation has been employed as a way to increase target lifetime. Also, in cases of lowmelting point target materials, rotating the target in the beam allows for increased heat dissipation, thus lowering loss of the target material. Rotating target wheels have been in use at ATLAS (Argonne Tandem Linac Accelerator System) for some time [1]. Various sizes and rotation schemes have been employed, each presenting new demands upon target preparation and mounting.

We will describe here a new, low-mass, rotating target wheel system for use within the Gammasphere target chamber. The design is based on a previously successful implementation of rotating target wheels for the Argonne Positron Experiment (APEX) as well as for the Fragment Mass Analyser (FMA).

\section{CHRONOLOGY OF THE DESIGN - THE APEX TARGET WHEEL}

The design of the Gammasphere target wheel is based directly on the original design used in the APEX experiment [2] with some modifications and improvements. Although a discussion of this target wheel is presented elsewhere [3], a short description is given here as many of the details of the present system are identical.

The APEX target wheel system consists of a stepper motor and shaft encoder located outside the vacuum chamber and coupled to the target wheel using a vertical drive shaft. The target wheel is comprised of a four quadrant frames made from $0.09 \mathrm{~cm}$ thick G-10 fiberglass making up a wheel of 5 $\mathrm{cm}$ in diameter. The target frame has a rounded trapezoidalshaped aperture of approximately $2.62 \mathrm{~cm}^{2}$ in area. A small slot in the comer of each frame allows it to slide into position on the hub where it is attached with a small screw. The APEX target wheel is able to rotate targets at a speed of $750 \mathrm{rpm}$. The system provides easy access for rapid target changes using a vacuum interlock.

The stepper motor controller is programmable in order to ramp up to full speed sufficiently slowly so as to avoid sudden accelerations which could rupture the targets. The output of the absolute shaft encoder is a 10-bit binary number (1024 channels). The encoder is read out by a CAMAC module designed and built at Argonne National Laboratory (ANL). This module provides two main functions. It produces a signal which triggers an electrostatic deflector [4] which sweeps the beam onto a slit in order to avoid hitting the target wheel spokes. The location of the spokes is stored in non-volatile memory. In addition, it also presents the position of the target wheel (obtained from the encoder) to the data acquisition system.

\section{FMA ROTATING TARGET SYSTEMS}

Four different rotating target schemes, including a modified version of the APEX target system, have been in use at the FMA within the gamma-ray target chamber [5]. This wheel uses four APEX type target frames. Target rotation is accomplished by a small DC motor drive and ferrofluidic feedthrough. As before, the motor drive also is connected to a digital shaft encoder, the output of which can be programmed to sweep off the beam to avoid bombarding

CP475, Applications of Accelerators in Research and Industry, edited by J. L. Duggan and I. L. Morgan

1999 The American Institute of Physics 1-56396-825-S 


\section{DISCLAIMER}

This report was prepared as an account of work sponsored by an agency of the United States Government. Neither the United States Government nor any agency thereof, nor any of their employees, make any warranty, express or implied, or assumes any legal liability or responsibility for the accuracy, completeness, or usefulness of any information, apparatus, product, or process disclosed, or represents that its use would not infringe privately owned rights. Reference herein to any specific commercial product, process, or service by trade -name, trademark, manufacturer, or otherwise does not necessarily constitute or imply its endorsement, recommendation, or favoring by the United States Government or any agency thereof. The views and opinions of authors expressed herein do not necessarily state or reflect those of the United States Government or any agency thereof. 


\section{DISCLAIMER}

Portions of this document may be illegible in electronic image products. Images are produced from the best available original document. 
the spokes. This assembly was operated successfully up to 1000 rpm for physics experiments at the FMA.

\section{GAMMASPHERE TARGET WHEEL}

\section{Motor Drive System}

The overriding design constraint for the Gammasphere target wheel is to minimize the mass of the drive system within the target chamber. This is necessary to avoid absorption of the gamma-rays being produced in the target and detected in the array. Figure 1 shows a photograph detailing the drive components within the chamber.

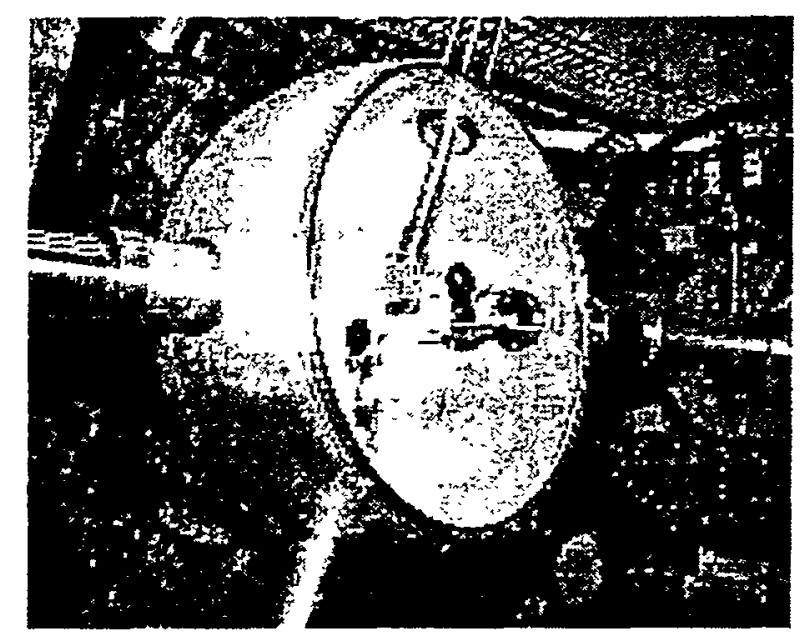

FIGURE 1. Photograph of the target wheel drive within the Gammasphere target chamber.

Rotation is accomplished by a motor driven shaft with the DC motor drive and encoder being located outside the vacuum chamber. The stainless steel shaft engages a twogear drive system making an angle of $64^{\circ}$ to the horizontal. The gears are made of aluminum and delrin. An aluminum hub and bracket, which can be disengaged from the drive system, holds the four-sector target wheel. This installed wheel system has been used in the stationary mode as well as at speeds of $300 \mathrm{rpm}$. With the beam sweeping activated to avoid the spokes, the duty factor for beam on target is approximately $80 \%$. Figure 2 presents a plot of encoder position vs. gamma and particle events for an experiment employing $400 \mu \mathrm{g} / \mathrm{cm}^{2}{ }^{208} \mathrm{~Pb}$ targets on carbon backings. The spoke structure and beam sweeping is readily apparent.

An additional consideration is the construction of the drive mechanism to rotate the wheel and mate with the target chamber once the Gammasphere array is in the closed position. There are four pentagonal openings located around the meridian comprising the bisected sphere halves. Two of these openings comprise the beam line. The third allows for
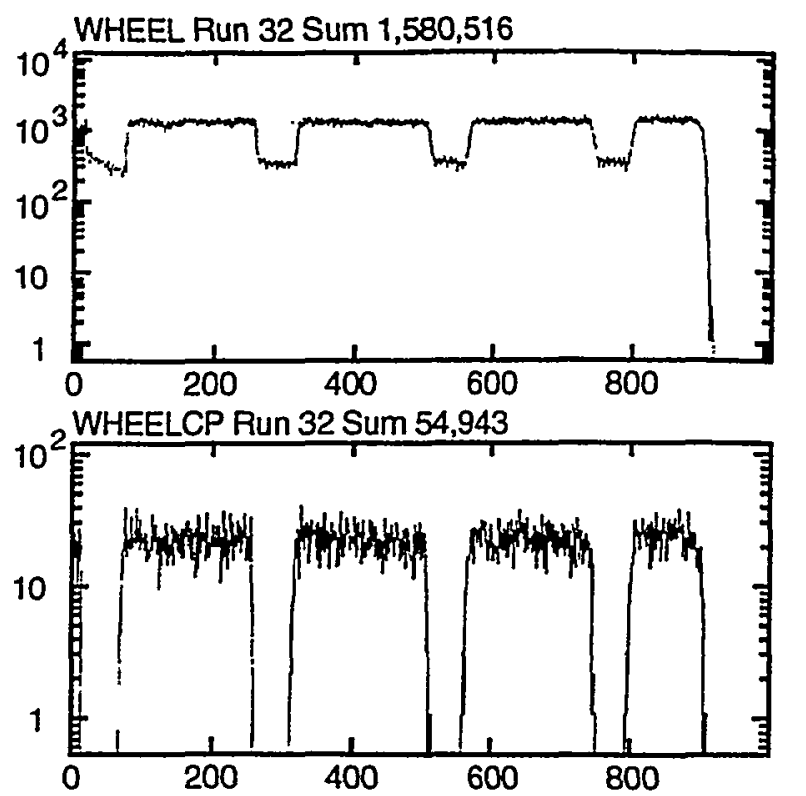

FIGURE 2. Plots of encoder position vs. events for a rotating target wheel consisting of $400 \mu \mathrm{g} / \mathrm{cm}^{2}{ }^{208} \mathrm{~Pb}$ on $8 \mu \mathrm{g} / \mathrm{cm}^{2}$ carbon backings. The upper histogram shows encoder position vs. total Gammasphere trigger events (gamma-rays). The lower histogram shows encoder position vs. FMA focal plane detector trigger events (particles).

the pedestal supporting the target chamber. The remaining accessible opening is used for the direct drive motor and encoder position readout module support structure. These are mounted on a series of concentrically smaller and smaller disks and a nested framework, finally mating with the vacuum chamber. Outside of the closed sphere, the upper end of the drive assembly is supported by a bracket to the overhead cable tray.

\section{Target Production and Performance}

The target wheels prepared for Gammasphere experiments are identical to those used for APEX [6], described above, except the frames are now made from $0.09 \mathrm{~cm}$ aluminum. Targets can be easily replaced once the chamber is vented to atmosphere and the cover removed by either disengaging the hub or, as has been the practice, by dismounting and remounting one quadrant sector at a time in situ.

As this rotating target system has only recently been developed, there have only been a few preliminary applications to date employing target wheels. Table 1 lists target wheels produced for these FMA/Gammasphere experiments. A recent experiment [7] involved moderate intensity, ( $5 \mathrm{pnA}$ ) ${ }^{48} \mathrm{Ca}$ beams of $216 \mathrm{MeV}$ beam energy and used $300-400 \mu \mathrm{g} / \mathrm{cm}^{2}{ }^{208} \mathrm{~Pb}$ targets on $8 \mu \mathrm{g} / \mathrm{cm}^{2}$ carbon backings, similar to those employed previously for measurements using APEX [8]. Many such wheels were 
TABLE I. Target wheels produced for FMA/Gammasphere experiments

\begin{tabular}{|c|c|c|c|c|}
\hline Target & Thickness $\left(\mu \mathrm{g} / \mathrm{cm}^{2}\right)$ & Backing Foil & Thickness $\left(\mu \mathrm{g} / \mathrm{cm}^{2}\right)$ & Number of Wheels Prepared \\
\hline${ }^{11} \mathrm{~B}$ & nom 1400 & $\mathrm{Ta}$ & $250 \mu \mathrm{m}$ & 1 \\
\hline${ }^{209} \mathrm{Bi}$ & 400 & $\mathrm{C}$ & 40 & 2 \\
\hline${ }^{12} \mathrm{C}$ & 50 & & & 1 \\
\hline $\mathrm{FeS}$ & 156 & $\mathrm{C}$ & 35 & 1 \\
\hline${ }^{62} \mathrm{Ni}$ & nom 1000 & & & 2 \\
\hline${ }^{208} \mathrm{~Pb}$ & 300 & $\mathrm{C}$ & 40 & 2 \\
\hline & 300 & $\mathrm{C}$ & 42 & 2 \\
\hline & 400 & $\mathrm{C}$ & nom 8 & 5 \\
\hline & 400 & $\mathrm{C}$ & 40 & 5 \\
\hline & 500 & $\mathrm{C}$ & 7 & 7 \\
\hline & 600 & $\mathrm{C}$ & 40 & 4 \\
\hline & 1000 & $\mathrm{C}$ & 7 & 1 \\
\hline${ }^{124} \mathrm{Sn}$ & nom 500 & $\mathrm{C}$ & 40 & 4 \\
\hline $96 \mathrm{Zr}$ & nom 700 & & & 1 \\
\hline
\end{tabular}

prepared for these extended runs. The lead targets performed well under beam exposure, only having to be replaced approximately once every 20 hours. Figure 3 shows a photograph of one such target after beam irradiation, the beam stripe is clearly visible.

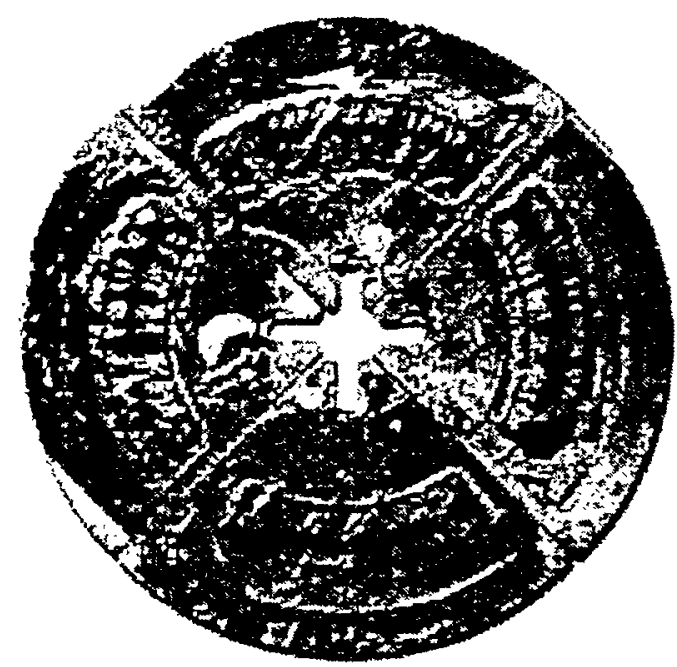

FIGURE 3. Photograph of a $400 \mu \mathrm{g} / \mathrm{cm}^{2}{ }^{2014} \mathrm{~Pb}$ on $8 \mu \mathrm{g} / \mathrm{cm}^{2}$ carbon backing wheel target after irradiation in the ${ }^{48} \mathrm{Ca}$ beam. The width of the beam $(-3 \mathrm{~mm})$ was obtained by wobbling using steerers in the beam line.

\section{CONCLUSION}

In conclusion, the successful implementation of a rotating target wheel system within the Gammasphere target chamber has made possible the use of higher beam currents on lowmelting point target materials, allowing for experiments to be carried out which were not possible before. The many targets that have been prepared and employed using this system have performed well in beam currents of $5 \mathrm{pnA}$, limited only by the Gammasphere detector rates.

\section{ACKNOWLEDGMENTS}

The authors would like to thank-Dr. Walter Henning, the Physics Division Director, and Dr. Irshad Ahmad, the Target Facility Group Leader, for their continuing encouragement and support of these efforts. This work is supported by the U.S. Department of Energy, Nuclear Physics Division, under Contract No. W-31-109-Eng-38, the National Science Foundation and the State of Florida.

\section{REFERENCES}

[1] G.E. Thomas, et al., Nucl. Instr. and Meth. 167 (1979) 29-31

[2] 1. Ahmad, et al., Nucl. Instr. and Meth. in Phys. Res. A370 (1996) 539-557

[3] D.E. Roa, et al., Nucl. Instr. and Meth. in Phys. Res. A368 (1996) 307-313

[4] J.M. Bogaty, Proc. 1989 IEEE Part. Accel. Conf., Chicago, II, 20-23 March 1989, eds. F Bennet and J. Kopta, vol. 1 (1989) pp. 595-597.

[5] V. Nanal, et al., Phys. Div. Ann. Report, ANL-97/14, (1996) p. 84

[6] J.P. Greene, G.E. Thomas and R.H. Leonard, Nucl. Instr. and Meth. in Phys. Res. A362 (1995) 81-89

[7] T.L. Khoo, et al., submitted.

[8] I. Ahmad, et al., Phys. Div. Ann. Report, ANL97/14 (1996) p. 69 